2011-12

\title{
An evaluation of the toxicity and bioaccumulation of cisplatin in the marine environment using the macroalga, Ulva lactuca
}

Easton, C

http://hdl.handle.net/10026.1/3706

10.1016/j.envpol.2011.08.018

Environmental Pollution

Elsevier BV

All content in PEARL is protected by copyright law. Author manuscripts are made available in accordance with publisher policies. Please cite only the published version using the details provided on the item record or document. In the absence of an open licence (e.g. Creative Commons), permissions for further reuse of content should be sought from the publisher or author. 


\title{
An evaluation of the toxicity and bioaccumulation of cisplatin in the marine environment using the macroalga, Ulva lactuca
}

\author{
Cecilia Easton ${ }^{\mathrm{a}}$, Andrew Turner $^{\mathrm{a}, *}$, Graham Sewell ${ }^{\mathrm{b}}$ \\ ${ }^{a}$ School of Geography, Earth and Environmental Sciences, University of Plymouth, Drake Circus, Plymouth PL4 8AA, UK
}

${ }^{\mathrm{b}}$ School of Health Professions, University of Plymouth, Peninsula Allied Health Centre, Plymouth PL6 8BH, UK

\section{A R T I C L E I N F O}

\section{Article history:}

Received 20 April 201

Received in revised form

15 July 2011

Accepted 8 August 2011

\section{Keywords:}

Cisplatin

Monoaquacisplatin

Ulva lactuca

Accumulation

Internalisation

Phytotoxicity

\begin{abstract}
A B S T R A C T
The cytotoxic drug, cisplatin (cis- $\left.\mathrm{PtCl}_{2}\left(\mathrm{NH}_{3}\right)_{2}\right)$, has been added to cultures of the marine macroalga, Ulva lactuca, under various experimental conditions. Both accumulation and internalisation over a $48 \mathrm{~h}$ period was greater when cisplatin was added to coastal sea water (salinity $=33$ ) from a distilled water solution than when added to either sea water or estuarine water (salinity $=16.5$ ) from a saline solution. This effect is attributed to the greater abundance of the more reactive monoaqua complex (cis$\left.\mathrm{PtCl}\left(\mathrm{OH}_{2}\right)\left(\mathrm{NH}_{3}\right) \frac{1}{2}\right)$ in the distilled water solution and kinetic constraints on its conversion back to cis$\mathrm{PtCl}_{2}\left(\mathrm{NH}_{3}\right)_{2}$ in sea water. Despite its mode of action at the cellular level, cisplatin added up to concentrations of $150 \mathrm{nM}$ did not incur a measurable reduction in the efficiency of photochemical energy conversion under any of experimental conditions tested.
\end{abstract}

(c) 2011 Elsevier Ltd. All rights reserved.

\section{Introduction}

The cytotoxic drug, cisplatin (cis- $\mathrm{PtCl}_{2}\left(\mathrm{NH}_{3}\right)_{2}$ ) has found widespread use in the treatment of various cancers and tumours (Mascaux et al., 2000; Boulikas and Vougiouka, 2003). Cisplatin itself is relatively unreactive but in aqueous solution the chloro ligands are replaced by water in a stepwise manner forming monoaquacisplatin (cis- $\mathrm{PtCl}\left(\mathrm{OH}_{2}\right)\left(\mathrm{NH}_{3}\right)_{2}^{\frac{1}{2}}$ ) and diaquacisplatin (cis$\left.\mathrm{Pt}\left(\mathrm{OH}_{2}\right)_{2}\left(\mathrm{NH}_{3}\right)_{2}^{2+}\right)$ (Berners-Price and Appleton, 2000):

cis- $\mathrm{PtCl}_{2}\left(\mathrm{NH}_{3}\right)_{2} \underset{k_{-1}}{\stackrel{k_{1}}{\leftrightarrow}}$ cis- $\mathrm{PtCl}\left(\mathrm{OH}_{2}\right)\left(\mathrm{NH}_{3}\right)_{2}^{+}+\mathrm{Cl}^{-}$

cis- $\mathrm{PtCl}\left(\mathrm{OH}_{2}\right)\left(\mathrm{NH}_{3}\right)_{2}^{+} \underset{k_{-2}}{\stackrel{k_{2}}{\leftrightarrow}}$ cis- $\mathrm{Pt}\left(\mathrm{OH}_{2}\right)_{2}\left(\mathrm{NH}_{3}\right)_{2}^{2+}+\mathrm{Cl}^{-}$

where $k_{1}, k_{-1}, k_{2}$ and $k_{-2}$ are the forward and reverse rate constants for the respective reactions. The products of hydrolysis, including deprotonated species, readily react with $\mathrm{N}$-donor ligands, such as the nucleobases of DNA. Resulting cross-linking renders it impossible for rapidly dividing cells to duplicate their DNA and systematic cell death occurs (Wang et al., 2004). Since the aqua complexes also

\footnotetext{
* Corresponding author.

E-mail address: aturner@plymouth.ac.uk (A. Turner).
}

react with other, non-target biomolecules, however, cisplatin is highly toxic and has been classified by the IARC as "probably" carcinogenic to humans (Morita et al., 1997).

Cisplatin is typically administered at doses on the order of $100 \mathrm{mg}$ per m $\mathrm{m}^{-2}$ of body surface and is eliminated relatively rapidly via patients' urine. Although quantities of Pt entering the aquatic environment in hospital and municipal wastes are considerably lower than those entering from the erosion of catalytic converters via vehicular emissions (Kümmerer et al., 1999), the former source is of greater concern because of the toxicity of the aquated ions. Despite the cytotoxic properties of these species, however, very little information exists on their biogeochemical behaviour and effects in natural aquatic systems from which to formulate environmental risk assessments. Curtis et al. (2010) examined the adsorption of cisplatin, added to river water, sea water and mixtures thereof, to estuarine sediment. Results were interpreted and modelled in terms of the adsorption of monoaquacisplatin and its salinity-dependent (or chlorinity-dependent) rate of formation. The phytotoxicity of cisplatin in fresh water was demonstrated by Supalkova et al. (2008). Specifically, growth inhibition of the vascular plant, Lemna minor, was observed after 96-h exposure to concentrations of cisplatin ranging from 5 to $160 \mu \mathrm{M}$.

In the present study, we aim to better understand the biogeochemical behaviour and toxicity of cisplatin in coastal waters, where the drug may enter from treated or untreated effluents either directly or via rivers and estuaries. As a test organism, we use 
the green macroalga, Ulva lactuca, a common member of seaweed communities in the littoral and sublittoral shores of NW Europe that is able to withstand moderately polluted conditions, tolerate a range of abiotic conditions (e.g. salinity), and accumulate a variety of contaminants (Han et al., 2007; Abdallah and Abdallah, 2008: Masakorala et al., 2008). U. lactuca is fast growing and photosynthetic products are rapidly converted into cell growth with a doubling time of about two days under optimal conditions (FrostChristensen and Sand-Jensen, 1990). Here, the organism is exposed to cisplatin up to concentrations of $150 \mathrm{nM}$ and chlorophyll$a$ fluorescence quenching is employed as a non-invasive measure of phytotoxicity. We also determine total cisplatin (as Pt) that is accumulated by the alga when exposed to variable concentrations of the drug, and empirically discriminate between Pt that is adsorbed and internalised. We compare results of experiments in which the drug is administered from a sea water stock, where it is predicted to exist largely as cis- $\mathrm{PtCl}_{2}\left(\mathrm{NH}_{3}\right)_{2}$, and a distilled water stock, where more reactive and potentially toxic aquated species are predicted to be greater in abundance.

2. Materials and methods

\subsection{Materials and reagents}

All plasticware and glassware used in the experiments and for sample digestion and analyte storage was soaked in $0.5 \mathrm{M} \mathrm{HCl}$ for at least $16 \mathrm{~h}$ and rinsed twice with distilled water before being used. Coastal sea water (salinity $=33 ; \mathrm{pH}=8.1$ ) used for culturing and experimental work was available on tap in the laboratory having been collected in bulk from Plymouth Sound (UK) at high water and filtered on-line through $0.6 \mu \mathrm{m}$. Analytical grade acids and salts were purchased from Fisher Scientific and a $1 \mathrm{mg} \mathrm{mL}^{-1}$, septum-sealed solution of cisplatin (CAS 15663-27-1) in $0.9 \% \mathrm{NaCl}$ and at $\mathrm{pH} 3.2-3.5$ was purchased from Teva Ltd (Leeds, UK). Immediately before the experiments commenced, a $3 \mathrm{mg} \mathrm{L}^{-1}$ working solution of cisplatin in either sea water or distilled water was prepared in a $10 \mathrm{~mL}$ volumetric flask by appropriate dilution of the original stock.

\subsection{Sampling}

Samples of $U$. lactuca were collected, as required, from intertidal rock pools at Wembury, a protected beach $7 \mathrm{~km}$ to the SE of Plymouth, between May and July 2010 , and were transported to the laboratory in sealed plastic bags containing local sea water. Samples were cleaned of particulate matter and epibionts and then acclimatised for about three days in laboratory sea water in aerated $10 \mathrm{~L}$ polyethylene tanks at $15 \pm 1{ }^{\circ} \mathrm{C}$ and under fluorescent lighting $\left(250 \mu \mathrm{mol} \mathrm{m}^{-2} \mathrm{~s}^{-1}\right.$ photosynthetic active radiation) for $12 \mathrm{~h}$ per day.

\subsection{Safety}

Because we employed a cytotoxic substance, a class II biological safety cabinet located in a designated laboratory was used for experimental work and for sample storage. The operator, having received training in the safe handling of cytotoxic storage. The operator, having received training in the safe handling of cytotoxic gown, powder-free latex gloves, safety goggles and medical cap), and pipette tips and containers used to store or transfer the cisplatin stock or working dilutions thereof were disposed of in a hazardous waste bin that was subsequently incinerated at $1200^{\circ} \mathrm{C}$

\subsection{Experimental}

As required, discs of $14 \mathrm{~mm}$ diameter and averaging $5.7+0.4 \mathrm{mg}(n=20)$ on a dry weight basis were cut from the central portions of thalli with the sharpened end of a polyethylene cylinder. Discs were acclimatised in a clear, $1 \mathrm{~L}$ polypropylene tank containing $500 \mathrm{~mL}$ of laboratory sea water on the sill of a window at room temperature $\left(19 \pm 2{ }^{\circ} \mathrm{C}\right)$. Three types of treatment were performed in quadruplicate on the window sill in a series of $150 \mathrm{~mL}$. Pyrex beakers that were continuously gitated on an orbital shaker at about $100 \mathrm{rpm}$. In treatment $1,100 \mathrm{~mL}$ of sea water, two discs of $U$. lactuca and a dose of cisplatin dispensed from the working solution in sea water were added to each beaker. Treatment 2 was conducted likewise but in "estuarine water" at a salinity of 16.5 , attained by mixing equal quantities of sea water and distilled water in the beakers. Treatment 3 proceeded as treatment 1 but cisplatin was added from the working solution prepared in distilled water. In timed exposures performed under each set of conditions and using a cisplatin concentration of $150 \mathrm{nM}$, the contents were incubated for a period of five days and the fluorescence of the same disc, retrieved using polyethylene tweezers, was measured after different time intervals $(0,0.5,2,5,16,24,48,72,96$ and $120 \mathrm{~h})$. In short-term exposures the contents were exposed to different concentrations of cisplatin $(10,25$, 50,100 and $150 \mathrm{nM}$ ) for a period of $48 \mathrm{~h}$ before the fluorescence of one disc was measured and both discs and a 2-mL aliquot of sea water were retrieved for subsequent Pt analysis. Sea water aliquots were diluted to $10 \mathrm{~mL}$ in $50 \mathrm{~mL}$ polypropylene centrifuge tubes using $0.5 \mathrm{M} \mathrm{HCl}$ while the first disc arising from each exposure was immersed in $10 \mathrm{~mL}$ of $3 \mathrm{mM}$ EDTA in $0.6 \mathrm{M} \mathrm{NaCl}$ for $10 \mathrm{~min}$ in order to liberate adsorbed cisplatin (Hassler et al., 2004). Residual discs and the second, unwashed discs were freeze-dried, weighed and subsequently digested individually in $3.5 \mathrm{~mL}$ of concentrated $\mathrm{HNO}_{3}$ in a series of $10 \mathrm{~mL}$ screw-capped Teflon beakers for $\mathbf{4 5}$ min using a CEM MDS-2000 microwave digester. Residual contents were re-dissolved in $0.5 \mathrm{M} \mathrm{HNO}_{3}$ and transferred to $10 \mathrm{~mL}$ volumetric flasks and diluted to mark with Milli- $Q$ water. Corresponding control experiments were undertaken as above, in both timed and short-term experiments, but in the absence of cisplatin.

\subsection{Analysis}

The chlorophyll- $a$ fluorescence of $U$. lactuca discs was determined throughout the timed treatments and at the termination of the short-term exposures using a Hansatech Instruments portable plant efficiency analysis meter. Discs were carefully shaken to remove excess water before being placed in individual leaf-clips in the beam of excitation light and the maximum fluorescence yield, $F_{\mathrm{m}}$ and initia fluorescence yield, $F_{0}$, recorded. The maximum quantum efficiency of photosystem I (PS II) is expressed as the ratio of variable $\left(F_{\mathrm{v}}=F_{\mathrm{m}}-F_{\mathrm{o}}\right)$ to maximum chlorophyll fluorescence.

Acidified filtrates and $\mathrm{HNO}_{3}$ digests were analysed for ${ }^{196} \mathrm{Pt}$ by inductively coupled plasma-mass spectrometry (ICP-MS) using a Thermo Scientific X Series I bench top mass spectrometer (Thermoelemental, Winsford, UK). Calibrations in the range 1-30 $\mu \mathrm{g} \mathrm{Pt} \mathrm{L}^{-1}$ were achieved using standards prepared by dilution of a Merck plasma emission solution of $\mathrm{Pt}(\mathrm{IV})$ in $0.3 \mathrm{M} \mathrm{HNO}_{3}$. Drift in instrument sensitivity was corrected for by the addition of $100 \mathrm{\mu g} \mathrm{L}^{-1}$ of ${ }^{193}$ Ir to all samples and standards, and a standard was analysed as a check after every ten samples. Platinum concentrations were corrected for any background Pt or interferences arising from the matrix of the aqueous phase or algal digests by subtracting average concentrations registered in the corresponding controls.

\section{Results}

\subsection{Influence of cisplatin on PS II}

The potential photochemical efficiency of PS II $\left(F_{\mathrm{v}} / F_{\mathrm{m}}\right)$ of U. lactuca exposed to cisplatin is shown in Fig. 1. In all three treatments and in both short-term $(48 \mathrm{~h})$ exposures employing variable cisplatin concentrations and in timed exposures employing the maximum concentration of cisplatin, values of $F_{\mathrm{v}} / F_{\mathrm{m}}$ did not differ statistically from the corresponding cisplatin-free controls ( $p>0.05$ according to one-way ANOVA).

\subsection{Accumulation of cisplatin}

In Fig. 2, the total concentration of cisplatin accumulated by U. lactuca over a 48-h period and on a dry weight-normalised basis, $\left[\mathrm{CP}_{\mathrm{T}}\right]$, is shown against the concentration of the drug remaining in solution, $\left[\mathrm{CP}_{\mathrm{aq}}\right]$, for the three different treatments. In each case, $\left[\mathrm{CP}_{\mathrm{T}}\right]$ was related to $\left[\mathrm{CP}_{\mathrm{aq}}\right]$ linearly and an accumulation factor, $\mathrm{AF}$ $\left(\mathrm{mL} \mathrm{g}^{-1}\right)$, was derived from the slope of the relationship:

$\mathrm{AF}=\left(\left[\mathrm{CP}_{\mathrm{T}}\right] \cdot 10^{3}\right) /\left[\mathrm{CP}_{\mathrm{aq}}\right]$

Values of AF, shown in Table 1, reveal that accumulation is greater in sea water than in estuarine water and is greatest in the treatment in which the drug was added from the solution prepared in distilled water. Also shown in Fig. 2 as a function of aqueous cisplatin is the dry weight-normalised concentration accumulated by $U$. lactuca that is resistant to an EDTA wash; that is, the concentration of cisplatin that is, by operational definition, internalised by the alga, $\left[\mathrm{CP}_{\text {int }}\right]$. Linear relationships between $\left[\mathrm{CP}_{\text {int }}\right]$ and $\left[\mathrm{CP}_{\mathrm{aq}}\right]$ indicate that, for each treatment, the degree of internalisation is independent of the quantity of cisplatin administered. The proportion of accumulated cisplatin that is internalised, derived from the slope of $\left[\mathrm{CP}_{\text {int }}\right]$ versus $\left[\mathrm{CP}_{\mathrm{aq}}\right]$ divided by the slope of $\left[\mathrm{CP}_{\mathrm{T}}\right]$ versus $\left[\mathrm{CP}_{\mathrm{aq}}\right]$ and shown in Table 1 , is about $60 \%$ for the 
treatments in which the drug was added from saline solution and nearly $80 \%$ in the treatment in which the drug was administered in distilled water. By difference, therefore, the respective proportions of cisplatin adsorbed to the alga are about $40 \%$ and $20 \%$. Adsorption constants, $K_{\text {ads }}\left(\mathrm{mL} \mathrm{g}^{-1}\right)$, defining this effect were derived from the slopes defining accumulation and internalisation:

$K_{\mathrm{ads}}=\left(\left[\mathrm{CP}_{\mathrm{T}}\right]-\left[\mathrm{CP}_{\text {int }}\right]\right) \cdot 10^{3} /\left[\mathrm{CP}_{\mathrm{aq}}\right]$

and are given in Table 1 for each experimental treatment.

\section{Discussion}

\subsection{Speciation of cisplatin}

Based on our analytical capability, results thus far have been described in terms of total Pt or cisplatin. Clearly, an understanding
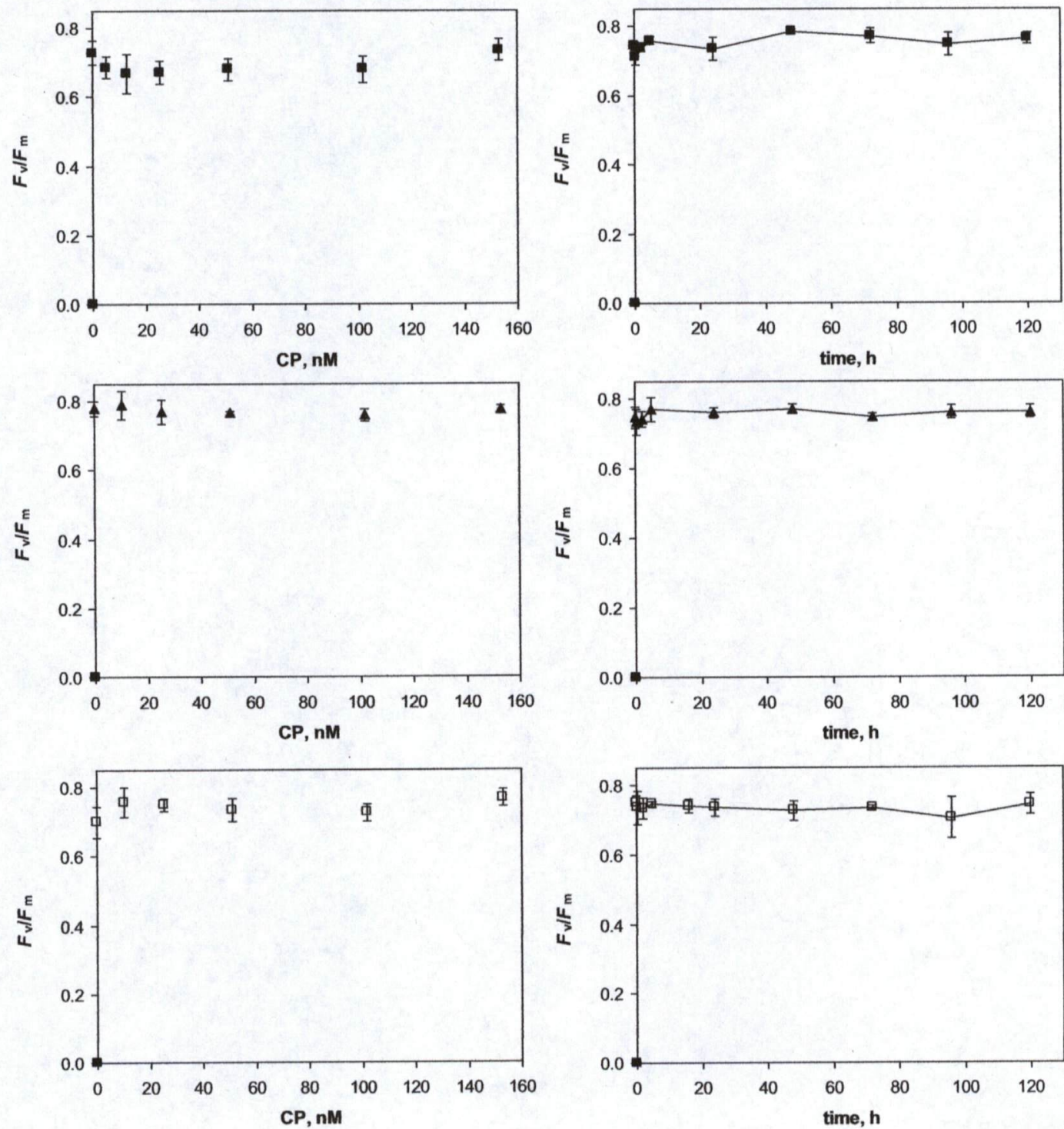

and mechanistic interpretation of the results reported above require knowledge of the speciation of cisplatin under the experimental conditions employed. A review of available kinetic constants by Berners-Price and Appleton (2000) suggests that, fo chloride concentrations of $100 \mathrm{mM}$ and $\mathrm{pH}$ values of about 7.4 , between 15 and $32 \%$ of cisplatin is converted to aquated forms and that monoaquacisplatin contributes up to about $7 \%$ of total cisplatin. However, it is important to appreciate that our experiments were conducted at a higher chlorinity and $\mathrm{pH}$ and in the presence of other inorganic and organic ions whose roles on reactions (1) and (2) are unknown. Moreover, because our exposures were conducted in the light, displacement of the chloride ligand is likely to be accelerated by photoaquation (Greene et al., 1979) while the aqua complex is predicted to gradually decay to undefined but less reactive species (Hann et al., 2003).

A semi-quantitative evaluation of the species present in our experiments may be gained from the rate constants derived
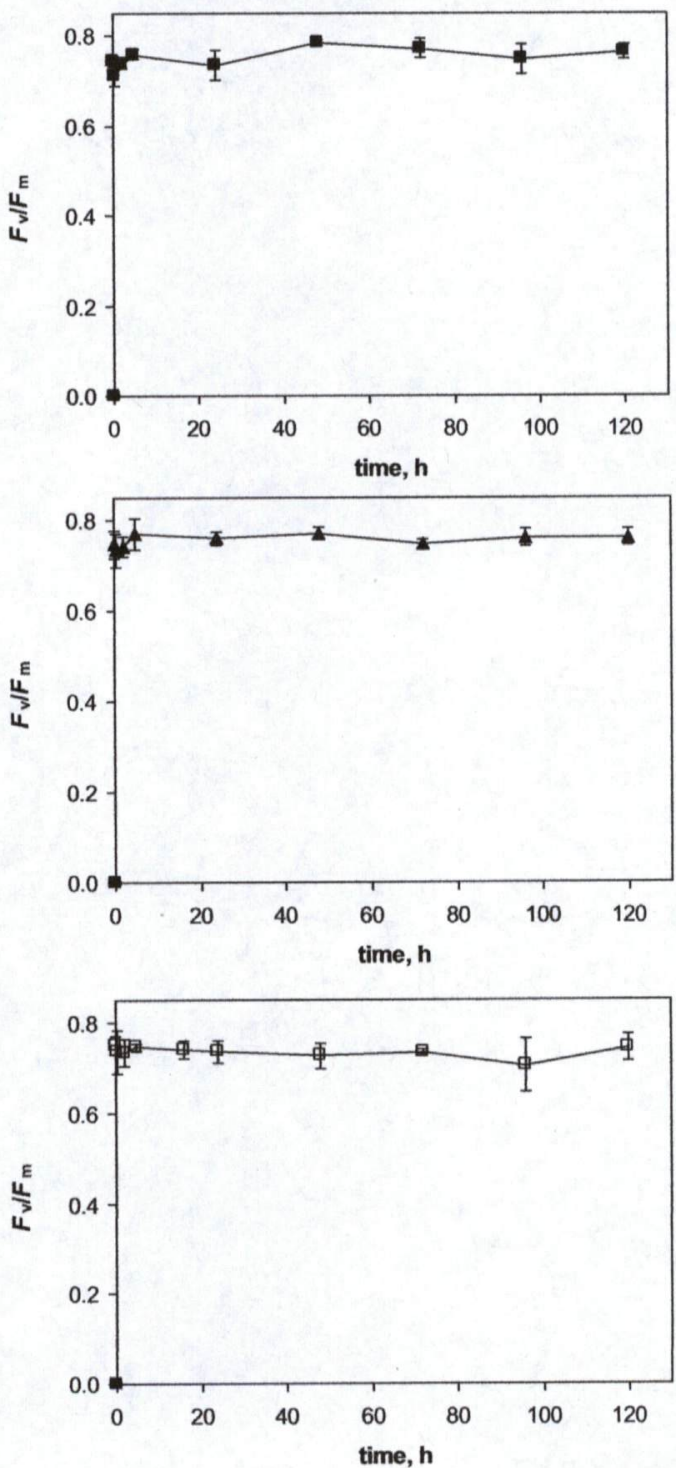

Fig. 1. Efficiency of photochemical energy conversion $\left(F_{\mathrm{v}} / F_{\mathrm{m}}\right)$ of $U$. lactuca as a function of added concentration of cisplatin after $48 \mathrm{~h}$ exposure (left-hand panels) and as function of time on exposure to $150 \mathrm{nM}$ of cisplatin (right hand panels) for treatments $1(\mathbf{m}), 2(\Delta)$ and $3(\square)$. Error bars represent one standard deviation about the mean of four measurements. 

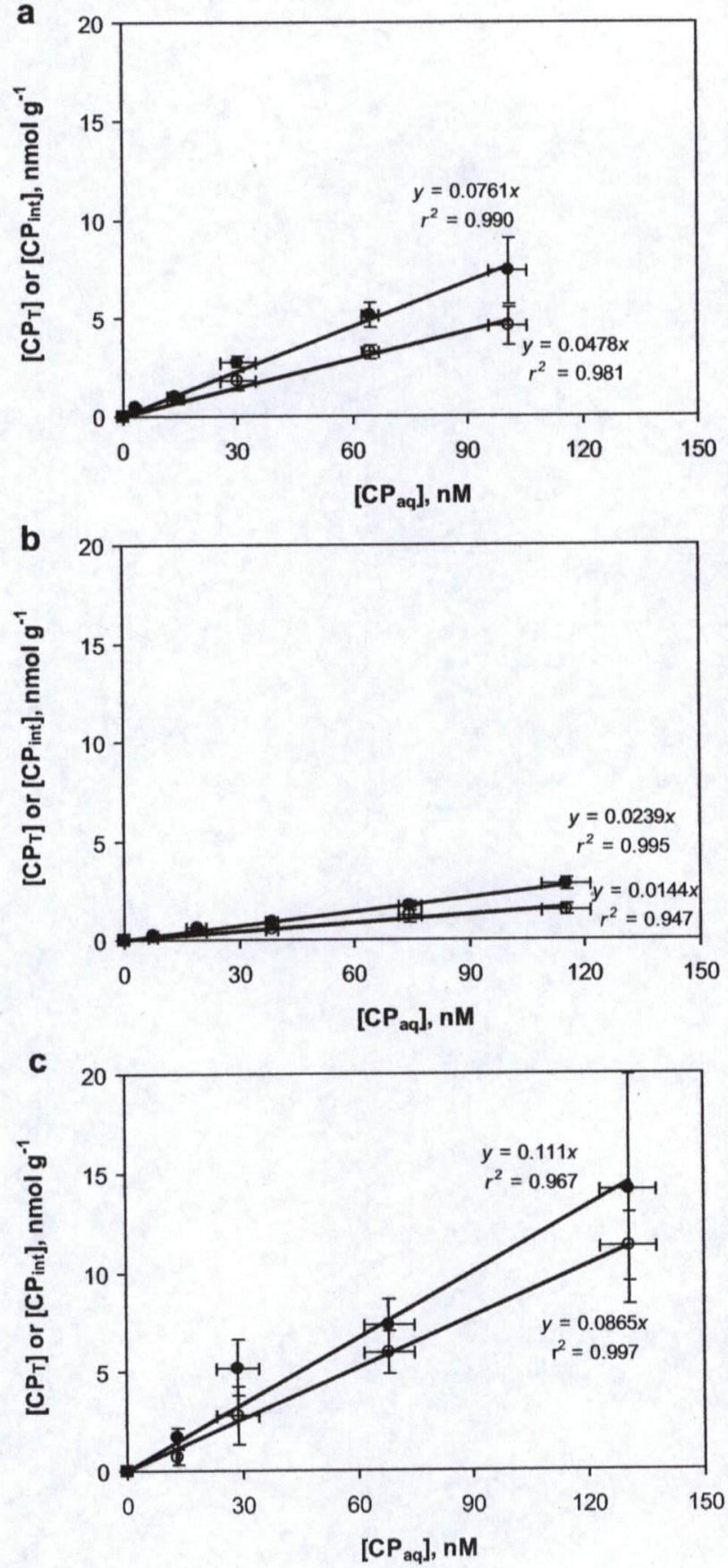

Fig. 2 Concentration of cisplatin accumulated by $U$. lactuca $\left(\mathrm{CP}_{\mathrm{T}}=\right.$ total, $\mathrm{CP}_{\text {int }}=$ internalised, O) as a function of concentration of cisplatin remaining in solution for treatments 1, 2 and 3 (a, b and c, respectively). Error bars denote one standard deviation about the mean arising from four experimental replicates.

empirically by Curtis et al. (2010). Specifically, these authors assumed that monoaquacisplatin is the only reactive species and obtained estimates of $k_{1}=5.50 \times 10^{-6} \mathrm{~s}^{-1}$ and $k_{2}=5.84 \times 10^{-6} \mathrm{~s}^{-1}$ in sea water (salinity $=33.3 ; \mathrm{pH}=8.2$ ) at room temperature and in the dark by fitting kinetic data defining the adsorption of cisplatin to estuarine sediment. Using the integrated form of the reversible conversion of cisplatin to monoaquacisplatin (Equation (1)):
Table 1

Constants defining cisplatin interactions with $U$. lactuca in the three treatments, as derived from the slopes of the relationships shown in Fig. 2.

\begin{tabular}{lclc}
\hline Treatment & $\mathrm{AF}, \mathrm{mL} \mathrm{g}^{-1}$ & Internalisation, \% & $K_{\text {ads. }} \mathrm{mL} \mathrm{g}^{-1}$ \\
\hline 1 & 76.1 & 62.8 & 28.3 \\
2 & 23.9 & 60.3 & 9.5 \\
3 & 111.1 & 77.9 & 22.3 \\
\hline
\end{tabular}

$$
\begin{aligned}
& {\left[\operatorname{cis}-\mathrm{PtCl}\left(\mathrm{OH}_{2}\right)\left(\mathrm{NH}_{3}\right)_{2(\mathrm{aq})}^{+}\right]_{t}=} \\
& \quad\left(k_{1} /\left(k_{1}+k_{2}\right)\right)\left[c i s-\mathrm{PtCl}_{2}\left(\mathrm{NH}_{3}\right)_{2(\mathrm{aq})}\right]_{0}\left(1-e^{-\left(k_{1}+k_{2}\right) t}\right)
\end{aligned}
$$

where subscripts 0 and $t$ refer to concentrations at time zero and time $t$, respectively, we calculated the percentage distributions of the two forms (or, strictly, the parent compound and all aquated complexes) in the exposure experiments. Thus, we predict that, when introduced to sea water from the saline stock (and [cis$\mathrm{PtCl}_{2}\left(\mathrm{NH}_{3}\right)_{2}$ (aq) lo = 100\%), about $40 \%$ of cisplatin is converted to aquated species in the short-term exposures and about $45 \%$ is converted by the end of the timed treatments. When introduced into sea water from the distilled water stock (assuming that [cis$\left.\operatorname{PtCl}\left(\mathrm{OH}_{2}\right)\left(\mathrm{NH}_{3}\right)_{2}{ }_{(\mathrm{aq})} \mathrm{l}_{0}=100 \%\right)$, nearly $60 \%$ and about $50 \%$ of cisplatin is predicted to exist as aquated complexes after $48 \mathrm{~h}$ and $120 \mathrm{~h}$, respectively.

\subsection{Likely mechanisms of cisplatin accumulation}

In the case of $U$. lactuca, contaminants appear to be able to interact with the algal surface both non-specifically (e.g. hydrophobically) and specifically (e.g. electrostatically) (Masakorala et al., 2008) and we surmise, therefore, that both cisplatin and monoaquacisplatin are reactive in the present experiments. For cisplatin:

cis- $\mathrm{PtCl}_{2}\left(\mathrm{NH}_{3}\right)_{2}(\mathrm{aq}) \underset{\boldsymbol{k}_{\text {des }}}{\stackrel{k_{\text {ads }}}{\leftrightarrow}}$ cis- $\mathrm{PtCl}_{2}\left(\mathrm{NH}_{3}\right)_{2 \text { (ads) }} \stackrel{k_{\text {int }}}{\rightarrow}$ cis- $-\mathrm{PtCl}_{2}\left(\mathrm{NH}_{3}\right)_{2 \text { (int) }}$

where $k_{\text {ads }}$ and $k_{\text {des }}$ are adsorption and desorption rate constants for the interaction of cisplatin with the algal surface, and $k_{\text {int }}$ is an internalisation rate constant. Equation (6) should not necessarily imply that interactions with cisplatin are entirely non-specific, however. This is because the drug is known to react directly with sulphur-containing ligands, akin to many functional groups at the algal surface, without the requirement for hydrolysis (Heudi et al., 1998). The formation of monoaquacisplatin and its subsequent interaction with $U$. lactuca proceeds as follows:

$$
\begin{aligned}
& \text { cis- } \mathrm{PtCl}_{2}\left(\mathrm{NH}_{3}\right)_{2(\mathrm{aq})} \underset{k_{-1}}{\stackrel{k_{1}}{\leftrightarrow}} \operatorname{cis}-\mathrm{PtCl}_{2}\left(\mathrm{OH}_{2}\right)\left(\mathrm{NH}_{3}\right)_{2(\mathrm{aq})}^{+} \\
& \underset{k_{\text {des } 1}}{\stackrel{k_{\text {ads } 1}}{\hookrightarrow} \text { cis- }} \mathrm{PtCl}\left(\mathrm{OH}_{2}\right)\left(\mathrm{NH}_{3}\right)_{2 \text { (ads) }}^{+} \stackrel{k_{\text {int }}}{\rightarrow} \text { cis- } \mathrm{PtCl}\left(\mathrm{OH}_{2}\right)\left(\mathrm{NH}_{3}\right)_{2 \text { (int) }}^{+}
\end{aligned}
$$

where $k_{\mathrm{ads} 1}, k_{\mathrm{des} 1}$ and $k_{\mathrm{int} 1}$ are the corresponding rate constants. Because of the density of negatively charged sites at the algal surface, both non-specific and electrostatic interactions of monoaquacisplatin are likely to occur.

Greater accumulation of the drug when administered from a distilled water solution than from a saline solution is consistent with the monoaqua complex being more reactive towards $U$. lactuca than cisplatin (either non-specifically or via its interaction with sulphur-containing functional groups). Greater internalisation under the former conditions suggests that the aquated 
complex also has a higher propensity to cross the cell membrane of the alga than the neutral, parent compound. In estuarine water, accumulation of Pt is predicted to be more favourable than in sea water because of the greater (negative) charge at the algal surface and both a higher proportion and greater activity of monoaquacisplatin at the reduced salinity. In the present experiments, however, it is unclear why greater accumulation of Pt was observed from sea water than estuarine water under otherwise identical conditions.

\subsection{General discussion}

The present work represents the first investigation the biogeochemistry or toxicity of any antineoplastic platinum-based drug in the marine environment. Despite the mode of action of the aqua complexes of cisplatin at the cellular level and the propensity for cisplatin to be internalised by $U$. lactuca, the drug is not measurably toxic to this important coastal primary producer up to concentrations of $150 \mathrm{nM}$, at least based on chlorophyll fluorescence quenching. Although total Pt concentrations of up to about $750 \mathrm{nM}$ have been reported in hospital waste waters (Lenz et al., 2005), concentrations considerably lower than our maximum experimental level are predicted in the environment after the treatment and subsequent dispersion of waste waters (Rowney et al., 2010).

The extent of accumulation of cisplatin by $U$. lactuca is not wholly consistent with thermodynamic or kinetic considerations in that interactions at the algal surface are greater in sea water than in estuarine water, despite the greater chloride concentration and lower abundance of the most reactive species (monoaquacisplatin) in the former. A more important factor in the accumulation of cisplatin by $U$. lactuca (and, likely, other biosolids and geosolids) appears to be the means by which the drug is introduced into the aqueous phase. Thus, administering cisplatin from a distilled water solution results in a doubling of the accumulation factor relative to that arising from introduction of cisplatin from a sea water solution. Greater uptake by the alga is, therefore, predicted when the drug is discharged in sewage effluent directly into coastal waters, largely as more reactive aqua complexes, than when discharged into fresh waters that indirectly enter the coastal environment via estuarine mixing, thereby allowing the gradual conversion of these complexes back to the parent drug. Regardless of the mode of introduction, however, U. lactuca appears to be able to accumulate and internalise Pt(II) and $\mathrm{Pt}(\mathrm{IV})$ ions more effectively than cisplatin or aquated complexes thereof. For example, Turner et al. (2007) obtained AF values for Pt(IV) of about $200-300 \mathrm{~mL} \mathrm{~g}^{-1}$ after an incubation period of $48 \mathrm{~h}$ at $15^{\circ} \mathrm{C}$, and internalisation of more than $90 \%$ after 100-h incubation. That the speciation of $\mathrm{Pt}(\mathrm{IV})$ in sea water is dominated by $\mathrm{PtCl}_{6}^{2-}$ and $\mathrm{PtCl}_{5} \mathrm{OH}^{2-}$ (Gammons, 1996) requires the free ion, $\mathrm{Pt}^{4+}$,to have both considerable affinity for the algal surface and a high propensity to cross the cell membrane.

Despite the relatively low reactivity and toxicity of cisplatin towards $U$. lactuca compared with many contaminants that are more abundant in the marine environment (Muse et al., 2006; Turner and Rice, 2010; Masakorala et al., 2011), it is not known whether other organisms (e.g. unicellular algae, invertebrates, fish) are more sensitive to the cytotoxin. Moreover, it is possible that the response is greater when other contaminants are present, including other cytotoxic Pt-based chemotherapy drugs (carboplatin and oxaliplatin) or substances whose modes of action are dissimilar (Johnson et al., 2008). Clearly, further research is required into the biogeochemical behaviour, effects and trophic transfer of a broader range of cytotoxins in fresh water, estuarine and marine environments.

\section{Acknowledgements}

We thank Mrs. Angela Harrop for assistance with the algal culturing and fluorescence measurements and Dr. Andrew Fisher for advice on the ICP-MS analysis.

\section{References}

Abdallah, M.A.M. Abdallah, A.M.A. 2008. Biomonitoring study of heavy metals in biota and sediments in the South Eastern coast of Mediterranean Sea, Egypt. Environmental Monitoring and Assessment 146, 139-145.

Berners-Price, S.J., Appleton, T.G., 2000. The chemistry of cisplatin in aqueous solution. In: Kelland, L.R., Farrell, N. (Eds.). Platinum-based Drugs in Cancer Therapy. Humana Press, Totowa, NJ, pp. 3-35.

Boulikas, T., Vougiouka, M., 2003. Cisplatin and platinum drugs at the molecular level (review) Oncology Reports 10, 1663-1682.

Curtis, L., Turner, A., Vyas, N., Sewell, G., 2010. Speciation and reactivity of cisplatin in river water and seawater. Environmental Science and Technology 44, 3345-3350.

Frost-Christensen, H., Sand-Jensen, K., 1990. Growth rate and carbon affinity of Ulva lactuca under controlled levels of carbon, $\mathrm{pH}$ and oxygen. Marine Biology 104, 497-501.

Gammons, C.H., 1996, Experimental investigations of the hydrothermal geochemistry of platinum and palladium: V. Equilibria between platinum metal, Pt (II), and Pt (IV) chloride complexes at 25 to $300^{\circ} \mathrm{C}$. Geochimica et Cosmochimica Acta 60, 1683-1694.

Greene, R.F., Chatterji, D.C., Hiranaka, P.K., Gallelli, J.F., 1979, Stability of cisplatin in aqueous solution. American Journal of Hospital Pharmacy 36, 38-43.

Han, Y.-K., Brown, M.T., Park, G.S., Han, T., 2007. Evaluating aquatic toxicity by visual inspection of thallus color in the green macroalga Ulva: testing a novel bioassay Environmental Science and Technology 41, 3667-3671

Hann, S., Koellensperger, G. Stefanka, Zs., Stingeder, G., Fürhacker, M. Buchberger, W., Mader, R.M., 2003. Application of HPLC-ICP-MS to speciation of cisplatin and its degradation products in water containing different chloride concentrations and in human urine. Journal of Analytical Atomic Spectrometry 18, 1391-1395.

Hassler, CS Slaveykova, V.I. Wilkinson, K.J., 2004. Discriminating between intraand extracellular metals using chemical extractions. Limnology and Oceanography: Methods 2, 237-247.

Heudi, O., Cailleux, A., Allain, P., 1998. Kinetic studies of the reactivity between cisplatin and its monoaqua species with t-methionine. Journal of Inorganic Biochemistry 71, 61-69.

Johnson, A.C., Jürgens, M.D., Williams, R.J., Kümmerer, K., Kortenkamp, A., Sumpter, J.P., 2008. Do cytotoxic chemotherapy drugs discharged into rivers pose a risk to the environment and human health? An overview and UK case study. Journal of Hydrology 348, 167-175.

Kümmerer, K., Helmers, E., Hubner, P., Mascart, G., Milandri, M., Reinthaler, F. Zwakenberg. M., 1999. European hospitals as a source of platinum in the environment in comparison with other sources. Science of the Total Environment 225. 155-165.

Lenz, K., Hann, S., Koellensperger, G., Stefanka, Z., Stingedeer, G., Weiseenbacher, N. Mahnik, N.S., Fuerhacker, M., 2005. Presence of cancerostatic platinum compounds in hospital wastewater and possible elimination by adsorption to activated sludge. Science of the Total Environment 345, 141-152.

Mascaux, C Paesmans, M., Berghmans, T., Branle, F., Lafitte, J.J., Lemaitre, F. Meert, A.P. Vermylen, P., Sculier, J.P., 2000. A systematic review of the role of etoposide and cisplatin in the chemotherapy of small cell lung cancer with methodology assessment and meta-analysis. Lung Cancer 30, 23-36.

Masakorala, K., Turner, A., Brown, M.T., 2008. Influence of synthetic surfactants on the uptake of $\mathrm{Pd}, \mathrm{Cd}$ and $\mathrm{Pb}$ by the marine macroalga, Ulva lactuca. Environmental Pollution 156, 897-904.

Masakoral K. Turner A Brown, M.T, 2011. Toxicity of synthetic surfactants to the marine macroalga, Ulva lactuca. Water, Air and Soil Pollution 218, 283-291.

Morita, T., Asano, N., Awogi, T., Sasaki, Y.F., Sato, S.I., Shimada, H., Sutou, S., Suzuki, T. Wakata, A. Sofuni, T., Hayashi, M., 1997. Evaluation of the rodent micronucleus assay in the screening of IARC carcinogens (groups 1,2A and 2B). The summary report of the 6th collaborative study by CSGMT/JEMS.MMS. Mutation Research $389,3-122$.

Muse, J.O., Carducci, C.N., Stripeikis, J.D., Tudino, M.B., Fernandez, F.M., 2006. A link between lead and cadmium kinetic speciation in seawater and accumulation by the green alga Ulva lactuca. Environmental Pollution 141, 126-130.

they, N.C. Johnson, A.C., Williams, R.J., 2010. Cytotoxic drugs in drinking water: a prediction and risk assessment exercise for the Thames catchment in the a prediction and risk assessment exercise for the Thames catchment in them. Environmental Toxicology and Chemistry 28, 2733-2743.

Supalkova, V., Beklova, B., Baloun, J., Singer, C., Sures, B., Adam, V., Huska, D. Pikula, J., Rauscherova, L., Havel, L., Zehnalek, J., Kizek, R., 2008. Affecting of aquatic vascular plant Lemna minor by cisplatin revealed by voltammetry. Bioelectrochemistry 72, 59-65.

Turner, A. Rice, L, 2010. Toxicity of tire wear particle leachate to the marine macroalga Ulva lactuce. Environmental Pollution 158, 3650-3654.

Wang. G.D., Reed, E Li, O0 2004. Molecular basis of cellular response to cisplatin chemotherapy in non-small cell lung cancer (review). Oncology Reports 12 955-965. 